\title{
The research of PPP mode for the public service supply
}

\author{
Huixia Ren, Hongyan Li* \& Rui Zhang \\ Shanghai University of Engineering Science, Shanghai, China
}

\begin{abstract}
The introduction of PPP mode for supplying public service in our country has the feasibility and necessity, but because of the immature experience and short development time, there are some problems about the system mechanism, laws and regulations and the process of operation. By building the PPP pattern of social coordination, we can realize the effective operation of the PPP mode in public service supply.
\end{abstract}

Keywords: PPP mode; public service supply; social coordination

With the development of economy and society, the public demand for public services is growing. Although China has made considerable progress in the public service, the government's public service level and quality has been greatly improved, but the contradiction between demand and supply of public services is growing, which puts serious impact on China's economic development, social progress and living standards. Therefore, we are committed to exploring effective way to supply public services, and effectively improve the level and quality of public service provision.

\section{REVIEW OF EXISTING IDEAS}

\subsection{Existing views}

Under the influence of the new public management movement and the new public service theory, domestic scholars have made rational analysis of issues and made active response to public service reform. Here, we will supply domestic scholars' public service insights summarized in the following few points:

(1) Market participation. Introduced the market competition mechanism into the supply of public services, improve the efficiency of government, change the government monopoly of public service supply situation and achieve competitive public services and privatization. Chen Zhenming refers to such views in the "Reinventing Government--The Commentary of

*Corresponding author: hongyanlishu@163.com
New Public Management Movement". Xiangguo Cheng, one famous scholar, also held the same opinion. They both think by market participation, the government can reduce the burden and improve the quality of public services, which will lead to great public benefit.

(2) Public service-oriented government. Public service-oriented government can realize scientific orientation and transform functions effectively at the guidance of people-oriented concept. There are some qualities of public service-oriented government, such as democratic government, limited government, the performance of government, responsible government, just government, government rule of law. Junpeng Li and Yongqing Li mention such opinions in their articles. They stress that the government should pay more attention to perform the functions of social management and public services beside economic regulation and market supervision, to provide equal basic public services for the public.

(3) Pluralism. Make a breakthrough in the market, government and social inertia of thinking either-or choice, learn new public management, governance theory and other analytical tools, form an effective way: government-led, private sector and the third sector participation. Thus greatly improve the quality, efficiency and effectiveness of public service delivery. Jifang $\mathrm{Xu}$ and Yicheng Zhou hold this view in the "triple failure of the supply of public services and innovation of public service provision model" Hansmann also mention similar idea in The Role of Nonprofit Enterprise. They advocate by the cooperative governance of government, private, non-profit organ- 
izations, citizens can get better public services, while build a new model of primary diverse supply of public services.

(4) PPP mode. PPP mode is a mode of project financing. The public sector through the establishment of partnerships with the private sector, the use of market mechanisms to increase, improve and optimize the supply of public goods and services, so as to realize the functions of government in the public sector. PPP mode has been widely used in transportation, medical, defense, education, justice, entertainment and other fields in foreign countries, and has achieved remarkable results. Xianglai Tang proposed such opinions in "the research of PPP mode for public goods supply" and "the fourth way for public goods supply -PPP mode". Yanfang Li, Wei Zhao also support PPP mode. They believe the PPP model as a public administration reform program, although there are still shortcomings, but it plays an important role in promoting the reform of public sector spending and improving spending efficiency. Thus it is an effective mode of supply of public goods and services. Therefore, the introduction of PPP model in public service supply in China, and also has very important value.

\subsection{Review of existing views}

By experts and scholars discussed above, we find that domestic scholars have achieved fruitful results in the study of new public management. Many scholars have been aware of the reality of the lack of effective supply of public services, so they committed to research new ways and means to enhance the supply of public services. Among them, the introduction of market competition mechanism and define government responsibility have been put on the agenda. In addition, because our country is in the process of economic and social transformation, the appeal to transform promoted the practice of the construction of public service-oriented government. Establish and improve the public service system as the construction of public service-oriented government's core mission, plays an important role in increasing the effective supply of public services process. There are some government and social capital points of view tend to strengthen cooperation and form government-led diverse organizations (government, the market, the third sector). In addition, some scholars fully draw on the prevalence of the PPP model, advocating this mode should be applied to the supply of public services.

Based on the above analysis, we found that no matter market participants or pluralism or PPP mode advocate government is no longer the sole provider of public services, various social organizations and enterprises also play a relevant effect in the supply of public services. PPP model as a form of government and social capital cooperation model, has been widely used in infrastructure, education, health care, protection of housing construction, endowment, community service and other fields in foreign countries, and have achieved fruitful results. But in our case, PPP mode in the supply of public goods and services in the field and has not been universal and did not form specific implementation framework and operational processes, government responsibility in which also is unclear. But our government takes PPP model application and promotion very seriously, which has been carried out the first batch of 30 government and social capital cooperation model (PPP) demonstration projects. How to make full use of the PPP model to strengthen public service delivery has become an important issue. Therefore, we studied on the basis of experts on everybody, to analyze defects of our current PPP model and suggest improvements path from the perspective of social coordination, thereby improving PPP mode of public service delivery.

\section{EXISTING DEFECTS OF PPP MODE}

In recent years, the Chinese government set high hopes on the PPP mode applied to public goods and services supply. However, due to the application of the PPP mode is still in its infancy, there are still a number of projects not signed, the specific operation and run facing defects of institutional mechanisms, legal regulations, operating procedures, etc., all of which need further improvement.

\subsection{Institutional mechanism is imperfect, management institutions are required to set up}

By International experience, the development of institutional mechanisms is at the forefront throughout the PPP construction. Britain set up a specialized infrastructure Council (IUK) to promote PPP in the Ministry of Finance, which is responsible for PPP planning, policy implementation and a series of work. Canada established Treasury Company of PPP, strengthening their PPP procurement skills and capabilities. Australia set up Infrastructure Australia, released a set of nationwide public-private partnership guidelines. And since 2013 our government decided to promote the use of the PPP model, the Ministry of Finance is regarded as the first responser of the reform of PPP, which is on the head of Vice Minister Wang Baoan, following participation of Economic Planning Division, Finance Division, Law Department, Budget Division, International Division and other related departments. In addition, our government also set up a government and social capital cooperation (PPP) centre to provide the necessary technical support and guarantee for the further advance of PPP. But the promotion of PPP is a complex task and also a systematic project, relying solely on a centre is not enough. It needs to work closely with all levels of government and the relevant functional departments. Therefore, governments at all levels and departments must establish the appropriate 
PPP promotion department, responsible for the implementation of the specific region or the department.

\subsection{Laws and regulations are not perfect, the legal system needs to be strengthened}

In September 2014, the Ministry of Finance issued "the notice on the promotion of the use of government and social capital model of cooperation issues," which is the first official document of the Ministry of Finance to promote PPP mode power since enacted. In December 2014, the Ministry of Finance issued "on the issuance of government and social capital cooperative mode operation guide", of which, the scope of the PPP model, has been described as social capital to participate in government project, while the government provides operational guidance and implementation guidelines to speed up the practice of PPP projects. The State Council also issued "focus on innovation in the field of investment and financing mechanism to encourage social investment guidance", stressed government protect the interests of PPP and improve risk prevention and supervision mechanism. In same period, the National Development and Reform Commission also issued "guidance for PPP contract". While many guidance documents have advocated, but considering the complexity of project selection, project identification and project implementation, there needs a special PPP law to provide appropriate behavior rules. From international experience, many Western countries have specific legislation on PPP mode, such as Britain, France, Greece and the United States. Therefore, the development of a comprehensive PPP law to promote PPP as a basic legal safeguard has become a trend, providing legal constraints of the operation of the project, making easily solve problems and difficulties by law.

\subsection{Operation of the process is not clear, the contract needs refinement}

PPP model is based on the existence of the contract, ownership of the concession agreement and ownership. On the basis of those, PPP mode can have different combinations, and various combinations can be called PPP. PPP mode applied in an existing facility or new facility or applied for expansion is different from each other. For existing facilities, you can use the service agreements, operation and maintenance agreements; for the expansion of an existing facility, you can use the lease - build - operate, buy - build operate, transfer, etc.; for new facilities, you can use construction - transfer - operate, construction - own operate or other means. Our PPP projects currently identified mainly with reference to the government procurement process and project bidding process, the project has not yet established an independent operational process, at the same time the way of public service provision has not clarified the definition.
Meanwhile, although the government has introduced PPP mode operation guide, but still lack a relatively standardized template, the specific code of conduct also needs further refinement, such as the basic structure PPP projects, including what elements and what standard PPP project is approved, how to evaluate existing PPP project, under different circumstances in which PPP mode should be used.

\section{IMPROVING PPP MODEL BASED ON SOCIAL SYNERGY}

In the PPP mode, public service is supplied by the government and social capital. The government has the right to identify, control and supervise the social capital and both exist in strong collaborative relationship in the target, which increases the effective supply of public service, promotes economic development and ensures social harmony. At the same time, the body synergy, coordination and management synergy also exists in the PPP mode. Based on the cooperative relationship, we put forward countermeasures and suggestions about the existing problems in the PPP mode in China.

\subsection{Body synergy: perfect the systems and mechanisms, strengthen the construction of institutions}

Body coordination refers to establishing a multilateral coordination mechanism, and strengthening the department linkage. In terms of the PPP mode, body synergy demands that the government should change the traditional social management concept which has single body and gives priority to the administrative control. It should set up the concept about the pluralistic governance, co-construction and sharing, and use the administrative, legal means, moral constraints to obtain approval from the private sector and come to the agreement between the government and private sector.

\subsection{Cooperation synergy: improve laws and regulations, strengthen the legal system}

Collaborative synergy refers to building a supportive environment for development, enhance the legal basis. UK firstly used the PPP model in the public service reform,. Currently its PPP model has been applied to various degrees in transportation, education and medical fields. This is mainly due to the British government's support and attention as well as groundbreaking PPP specific legislation. In July 2014, the Kuwaiti parliament passed "PPP Law", which is regarded as an incentive of domestic and foreign investors, so that investors can develop large-scale projects on land provided by the Government. Project contract is valid for 40 years according to the original "BOT Law", 
now increases to 50 years. There is a huge difference between the provinces due to the economic and social development, so our country needs a special legal norm of PPP. Therefore, the government should expeditiously enact appropriate laws and regulations to constrain the behavior of the parties involved in PPP projects, make them stand on the just position, safeguard the fundamental interests of the broad masses of the people.

\subsection{Management synergy: implementation of a comprehensive management, standardized operation procedures}

Management synergy refers to the implementation of comprehensive management, strengthen the code of conduct. PPP project involves all types of public goods and public services, content of public goods and services are different, the specific operation of the PPP model is also more or less different. In order to allow the development of PPP model more standardized, there must be a relatively standard process. Therefore, four phases designed for our national public services PPP. 1) The preparation stage. The government determines public service supply project and the development of public service delivery standards, while private sector concerns of the government policy information, weighs the possibility of cooperation. 2) The procurement phase. The private sector submits an application to government, while government makes choice based on the manpower, material, financial and other information of private sector provided, with the signing contracts and financing cooperation. 3) The construction or reconstruction phase. According to the private sector, PPP contract calls for the construction or renovation of infrastructure of public services supplied. 4) Operational recovery stage. Private sector operates contracts in accordance with the contract of public service infrastructure to ensure the provision of public services, through user charges and the government pay for the necessary investment. After a period of operation, the private sector needs to return it to government or continue to operate. In addition, supervision of government departments should throughout the operation of the process should always, because the government has more responsibility for PPP projects than other bodies. All of people can benefit to the effective supply of public services under the PPP mode.

\section{THE EFFECTIVENESS OF PPP MODE}

There are so many advantages to improve PPP model based on social synergy, such as avoiding cost overruns, reducing the financial burden, allocating supply risk and so on, which all means the effectiveness of PPP mode. And the specifically description is suggested as follows.

\subsection{Avoid cost overruns}

When it comes to effectiveness of PPP mode, avoiding cost overruns cannot be ignored. The behavior that introducing PPP mode into public service supply means private sectors participate in the construction of public infrastructure with government or supply public service with government, which can play a supervisory role to each other. And when this project is completed or approved by government, private sectors can have the chance to obtain appropriate benefits. It can not only help improve the efficiency of public service supply, but also help reduce the cost overruns of project. In addition, and the risk of project funds also get effectively avoided.

\subsection{Reduce the financial burden}

By applying PPP mode, government is more likely to get relief of heavy transaction, whether big or small. Therefore government has more time to supervise the implementation of public infrastructure projects or the supply of public service, which plays an important role to reduce the government financial burden. What's more, at the same time, the government and private sectors can learn from each other, and compensate for lack of another. Therefore, a win-win situation is formed, which boosts the supply of public service to a large extent.

\subsection{Allocate the supply risk}

No matter provided by government lonely or by private sector lonely, there necessarily exists inconvenient troubles in the supply of public service, such as low efficiency of government or the loss of equity of private sector. Thereby using PPP mode to supply public service, not only the financing risk of contractors and investors can achieve a reasonable allocation, but also the supply risk can be effectively reduced, because the private sector will get the government's all kinds of help, from construction to operation, management.

\section{CONCLUSION}

The promotion and use of PPP model is not only a micro-level "mode upgrade", but also a macro-level institutional reform in the field of public service. After pouring into the massive funds, including corresponding international experience, proper project plan, completely construction of legal system and close cooperation in various departments are indispensable. Thus, we pin our hope on optimizing the present PPP mode through social cooperation to achieve adjustment of industrial structure, stability of growth, advance development, benefit livelihood and enterprise. 


\section{ACKNOWLEDGEMENT}

This paper is sponsored by Humanity and Social Science Youth foundation of Ministry of Education of China (GN: 15YJCZH232), Key project of Shanghai

Education Research and Innovation (14ZZ157), Graduate Innovation Project of Shanghai University of Engineering Science (E1-0903-15-01108).

\section{REFERENCES}

[1] Owen Hughes. 2013. Introduction to Public Administration, Beijing: Renmin University of China Press, 11.

[2] Zhenming Chen. 2012. Public Management, Beijing: Renmin University of China Press, 10.

[3] UK Treasury. 2012. A New Approach to Public Private Partnerships, London: Grown.

[4] Xianglai Tang. 2005. Study of PPP mode for the supply of public goods, Chinese Economic Issues.

[5] Xianglai Tang. 2006. The Fourth Way--PPP mode for the supply of public goods, Economic Survey.

[6] Yanfang Li, Wei Zhao. 2012. Study of rural public cultural products and services from the PPP perspective, Economic. 